\title{
Determinacy Analysis of Weights as Mathematical Basis of the Future Sociology
}

\author{
Yuri G. Dmitriev, Peter F. Tarassenko \\ Institute of Applied Mathematics and Computer Science \\ Tomsk State University \\ Tomsk, Russia \\ dmit@mail.tsu.ru,ptara@mail.tsu.ru
}

\author{
Yuri K. Ustinov \\ Management Technologies Development Laboratory \\ Tomsk State University \\ Tomsk, Russia \\ ustinov-yuk@mail.ru
}

\begin{abstract}
The mathematical method for processing data of a sociological survey is considered, taking into account the significance of respondents' opinions. Similarly to the S.V.Chesnokov's determinacy analysis (DA) of frequencies, a determinacy analysis of weights (DAW) is constructed in which the intensities and capacities of determinations are calculated by other formulas that allow taking into account the knowledge, life experience and professionalism of the respondent in the subject area.
\end{abstract}

Keywords- determinacy analysis, significance of the respondent opinion, evaluation of the population satisfaction with the public services, management sociology

\section{INTRODUCTION}

The study of the internal state of the social environment and undergoing social processes is the main task of sociology. There are many ways to penetrate into this environment, among which the simplest, fastest and most reliable method is a direct sociological survey.

Recently, for example, sociologists of many countries are actively exploring the satisfaction of societies with the quality and quantity of state and municipal services provided to them [1-9]. In Russia, these works are regulated by Presidential Decree No. 607 of April 28, 2008, "On Evaluating the Efficiency of Local Self-Government Bodies in the Urban Districts and Municipal Areas" and the Russian Federation Government Resolution No. 1313-r of September 11, 2008. According to these documents, using sociological survey of the population of the urban district (municipal district), it is necessary to identify the level of satisfaction of the population with the activities of local government bodies, as well as with public services provided at the municipal level. The obtained quantitative characteristics should be used for the decision making on personnel and financing issues of municipalities (the RF Government resolution No. 1317 of December 17, 2012).

\section{Determinacy ANALYSIS By FreQuencies}

To solve such kind of problems, special methods for conducting interviews, methods of mathematical processing of survey results, methods of sociological, economic, managerial analyses are being developed. For example, when analyzing "satisfaction..." a respondent is offered a questionnaire in which he can point out one of three answers against each question: "satisfied", "not satisfied", "difficult to answer". When the questionnaires are processed, the positive answers are marked with number +1 , negative ones with number -1 , and neutral ones with number 0 . After this, various relative fractions of certain properties are calculated in the context of other properties. These estimates allow discovering some of the necessary properties of societies. More fully, these properties are revealed in the analysis of determinations, the theory of which is described in the book of S.V. Chesnokov [10], some applications can be found [11-13]. For values $a$ and $b$ of properties $A$ and $B$ of the socium, S.V.Chesnokov considers a point (local) correspondence $a \rightarrow b$ (read "from $a$ to $b$ "), which he calls determination, if two quantities are defined

$$
I(a \rightarrow b)=\frac{N(a, b)}{N(a)} \quad \text { and } \quad C(a \rightarrow b)=\frac{N(a, b)}{N(b)}
$$

Here, $N(a), N(b)$ and $N(a, b)$ are simply the numbers of those parts of the respondents that possess the values of $a, b$, and both together, respectively. The first of the values in (1) estimates the fraction of the value $a$ used to form the value $b$; it is called the intensity (accuracy) of determination $a \rightarrow b$. The second one evaluates the proportion of the value $b$ created with the value $a$; it is called the capacity (completeness) of determination $a \rightarrow b$. If the property $A$ with the value $a$ actively participates ( $I$ is large) in the creation of the value $b$ of the property $B$, and thus contributes to the appearance of a notable fraction ( $C$ is large) of the property $B$ in the value $b$, we seem to have the right to infer the effect of the property $A$ in the value of $a$ on property $B$ in the value $b$. If the property A with the value $a$ actively participates ( $I$ is large) in the creation of the value $b$ of the property $B$, but it does not create a notable fraction ( $C$ is small) of the property $B$ in the value $b$, we seem to have the right to conclude that the property $B$ in the value $b$ is not affected by the property $A$ in the value $a$. Conversely, if the property $A$ with the value $a$ is not actively involved ( $I$ is small) in the creation of the value $b$ of the property $B$, and a significant fraction ( $C$ is large) of the value $b$ of the property $B$, then we seem to have the right to state the decisive influence of the property $A$ in the value $a$ on the formation of property $B$ in the value $b$. Finally, what conclusion could we make if both characteristics of determination $a \rightarrow b$ turn out to be small? The conclusion is that the properties of $A$ and $B$ are independent in the values of $a$ and $b$. However, this conclusion, as well as the previous ones, is still insufficiently substantiated.

In order to understand this, we normalize all the quantities involved in the formation of intensity and capacity of determination, by dividing them by the total number $N$ of respondents:

$$
\frac{N(a)}{N}=P(a), \quad \frac{N(b)}{N}=P(b), \quad \frac{N(a, b)}{N}=P(a, b)
$$

Denoting these relations by $P$, we explicitly point out the obvious analogy of relations (1) with the conditional probabilities from probability theory: 


$$
\begin{aligned}
& I(a \rightarrow b)=\frac{\frac{N(a, b)}{N}}{\frac{N(a)}{N}}=\frac{P(a, b)}{P(a)}=P(b \mid a) \\
& C(a \rightarrow b)=\frac{\frac{N(a, b)}{N}}{\frac{N(b)}{N}}=\frac{P(a, b)}{P(b)}=P(a \mid b)
\end{aligned}
$$

So we establish the similarity of the deterministic analysis (DA) to the probability theory [14]. This analogy immediately brings the first fruits. The matter is that the question of the independence of events in probability theory has been studied a long time ago, and as applied to the values $a$ and $b$ of the properties $A$ and $B$ of the society, it looks like this: the values $a$ and $\mathrm{b}$ of the properties $A$ and $B$ are independent if and only if $P(a, b)=P(a) P(b)$, i.e. when

$$
N \cdot N(a, b)=N(a) N(b)
$$

This relation gives us grounds to use the absolute difference $\boldsymbol{\Delta}(\alpha, b)=|N \cdot N(a, b)-N(a) N(b)|$ as a measure of the dependence of the values $a$ and $b$ of the properties of $A$ and $B$.

As for the cases mentioned above, they should be considered together with the value of $\Delta$. For example, if $N(a, b)=0$, then $I=0$ and $C=0$, but we cannot imply the independence of the values $a$ and $b$ of the properties $A$ and $B$, since $\boldsymbol{\Delta}(a, b)=N(a) N(b)>0$.

\section{Determinacy ANALYSis By Weights}

Formulas (1) clearly show that in DA the opinions of all respondents are considered to be equivalent, equally important. But two opinions about the medical services cannot be considered identically qualified, if one opinion comes from a young man, who almost does not need medical care, and another one is an opinion of old man who needs medicine almost every day. The same can be said about the opinions of professionals (who know everything about the subject of the issue, or almost everything), and the opinions of amateurs (who know a little or nothing about the subject area). Pythagoras taught that the judgment of one knowledgeable person weighs more than the chatter of a myriad of ignoramuses. The lack of differentiation in the significance of the opinions of professionals and amateurs leads to the deviation of the collective opinion estimator on the subject as compared to the real opinion. Understanding these issues leads to the need to take into account the significance of respondents' opinions when analyzing the results of sociological surveys. Having realized the significance of the respondent's opinion as his weight and denoting it through $w$, we come to the necessity of constructing a determinacy analysis of weights (DAW), in which the intensity and capacity of determinations are calculated by the formulas

$$
I(a \rightarrow b)=\frac{W(a, b)}{W(a)} \text { and } C(a \rightarrow b)=\frac{W(a, b)}{W(b)}
$$

Here $W(a), W(b)$, and $W(a, b)$ are simply the weights of those parts of the respondents that possess the properties $a, b$, and both together, respectively. For instance, in [15] regular amounts $N(\cdot)$ replaced with scores $W(\cdot)$, where

$$
\begin{gathered}
W(a b)=\sum_{i=1}^{N} w\left(x_{i}\right) \chi_{a}\left(x_{i}\right) \chi_{b}\left(x_{i}\right) \\
W(a)=\sum_{i=1}^{N} w\left(x_{i}\right) \chi_{a}\left(x_{i}\right) \\
W(b)=\sum_{i=1}^{N} w\left(x_{i}\right) \chi_{b}\left(x_{i}\right)
\end{gathered}
$$

$N$ is the total number of respondents (sample size), $\mathbf{x}_{\mathbf{i}}$ is the $i$ th respondent, $\mathbf{w}\left(\mathbf{x}_{\mathbf{i}}\right)$ is individual significance of the respondent answer to the given question, $\boldsymbol{X}_{\mathbf{a}}\left(\mathbf{x}_{\mathbf{i}}\right)$ is indicator function that takes value 1 if the respondent $\mathbf{x}_{\mathbf{i}}$ has the property $a$ and $\chi_{\mathbf{a}}\left(\mathbf{x}_{\mathbf{i}}\right)=\mathbf{0}$ otherwise. Note that if all responses are equally significant, i.e. $\mathbf{w}\left(\mathbf{x}_{\mathbf{i}}\right) \equiv \mathbf{1}$, then the score equals to regular frequency, i.e. $W(S)=N()$ and we have regular intensity and capacity (1) as the special case of (3).

It is clear that the DAW arising in this case is constructed similarly to the DA of frequencies, constructed by S.V. Chesnokov. The relationship between these theories is the same as that between probability theory in a classical probability space (with equiprobable outcomes) and probability theory in a general discrete probability space (in which the probabilities of outcomes are arbitrary within the limits of what is permissible). The transition from the classical probability space to the general discrete probability space unlimitedly expanded the scope of the probability theoretical methods in applied problems of physics, chemistry, biology, engineering, economics, etc. If additionally to the frequencies we can involve the information on relation of the society members to the subject of the researched social phenomena, it will allow us to understand better the issue under discussion and make more adequate decisions.

Let's take a closer look at the use significance of respondents' opinions. Most available source of information on the level of knowledge and expertise of a respondent in the particular subject area is the respondent himself. Therefore, the questionnaire next to the column for answering questions requires a column to assess the expertise of the respondent's opinion on each issue separately. If we consider a case when the expertise of respondent is assessed on a five-point scale, than the expected response can vary from 0 to 4 . The introduction of such a column in the questionnaire makes the task of the respondent slightly more complicated, but not so much as to abandon it at the expense of approaching the truth. The questionnaires received as a result of a poll are digitized and subjected to mathematical processing. Powerful 
spreadsheet tools can safely handle arrays containing many thousands of questionnaires.

\section{ILLUSTRATIVE EXAMPLE}

In this section we apply the methodology of determinacy analysis to data of the survey that conducted by sociologists of Tomsk State University in 2012 in one of the districts of Tomsk Oblast (Russia). The purpose of the survey was to study satisfaction of the population of the district with the functioning of local Administration and municipal services.

The study was conducted as a formalized "face to face" interview with the inhabitants of the main settlements. Sample size was 567 people, $5.3 \%$ of the total number of voters of the district. There were $49 \%$ of man, and $51 \%$ of women. The percent of age group 18-34 years was 30\%, 39\% of respondents were from 35 to 54 years old, and $31 \%$ were over 55 years old. The sample size was calculated on the basis of the official information on the number of voters in the district as of July 1, 2012.

The answers of respondents were recorded in the interview forms (questionnaires), which contain information about the satisfaction of the population with local authorities and municipal services. We will consider the following list of questions.

1. Are you satisfied with the quality of health care that hospitals provide in your settlement?

2. Are you satisfied with the quality of education, which is provided in the schools of your settlement?

3. Are you satisfied with the quality of preschool education in kindergartens of your settlement?

4. Are you satisfied with the quality of supplementary education for children in the clubs, art schools, music schools, etc.?

5. Are you satisfied with the quality of cultural services that provide cultural institutions of your settlement?

6. Are you satisfied with the housing and communal services?

7. Age: 1 - from 18 to 34 years old (young), 2-from 35 to 54 years (senior), 3-over 55years (old).

8. Gender: 1 -male, 2 - female.

Consider the case when the individual "satisfaction" is assessed using three levels: positive, negative, and neutral. According to determinacy analysis approach we can measure the satisfaction of community (or a part of community, a group) by intensity and capacity of three determinations "group $\rightarrow$ positive", "group $\rightarrow$ negative", "group $\rightarrow$ neutral".

It gives us the following values to analyze:

$$
\begin{array}{ll}
U^{+}=I(\text { group } \rightarrow \text { positive }), & V^{+}=C(\text { group } \rightarrow \text { positive }), \\
U^{-}=I(\text { group } \rightarrow \text { negative }), & V^{-}=C(\text { group } \rightarrow \text { negative }), \\
U^{o}=I(\text { group } \rightarrow \text { neutral }), & V^{o}=C(\text { group } \rightarrow \text { neutral }) .
\end{array}
$$

Based on that, we can describe satisfaction with two sets of intensity $U=\left\{U^{+}, U, U^{o}\right\}$ and capacity $V=\left\{V^{+}, V, V^{o}\right\}$.

In the table 1 and the table 2 we present the intensity and capacity of determinations "group $\rightarrow$ assessment". We indicate context in the table with the pair of digitized answers to the questions 7 and 8 , for example, $(1,2)$ means the group of young women, $\left(2,{ }^{*}\right)$ indicates the group of all senior people. For the convenience of the reader, we have identified the maximum value in each row with the bold font, and the minimum value in the row is underlined. To simplify referencing to the elements of the table we numbered both rows and columns.

Tables 1 and 2 can be studied by different ways depending on the initial hypothesis, which must either be confirmed or rejected.

In the table 3 we suggest a version of evaluation of the group significance for each survey question. Finally, for comparison, the table 4 selectively presents the results of calculating the intensities taking into account the weights from the table 3 , table 5 presents capacities calculated using weights from the table 3 . 
TABLE I. INTENSITY OF DETERMINATIONS "GROUP $\rightarrow$ ASSESSMENT"

\begin{tabular}{|c|c|c|c|c|c|c|c|c|}
\hline \multirow{2}{*}{ № } & \multirow{2}{*}{$\begin{array}{l}\text { Con- } \\
\text { text }\end{array}$} & \multirow{2}{*}{$\begin{array}{c}\text { Inten- } \\
\text { sity }\end{array}$} & \multicolumn{6}{|c|}{ Survey questions } \\
\hline & & & 1 & 2 & 3 & 4 & 5 & 6 \\
\hline 1 & young & $U+$ & 0,34 & 0,28 & 0,41 & 0,25 & $\underline{0,19}$ & 0,36 \\
\hline 2 & male & $U-$ & $\mathbf{0 , 4 7}$ & 0,10 & $\underline{0,05}$ & 0,10 & 0,23 & 0,20 \\
\hline 3 & $(1,1)$ & $U^{o}$ & $\underline{0,19}$ & 0,63 & 0,54 & 0,65 & 0,58 & 0,43 \\
\hline 4 & senior & $U+$ & 0,26 & 0,39 & $\underline{0,21}$ & 0,30 & 0,26 & 0,34 \\
\hline 5 & male & $U-$ & $\mathbf{0 , 4 9}$ & $\underline{0,04}$ & $\underline{0,04}$ & 0,06 & 0,15 & 0,27 \\
\hline 6 & $(2,1)$ & $U^{o}$ & $\underline{0,25}$ & 0,57 & 0,76 & 0,64 & 0,59 & 0,39 \\
\hline 7 & old & $U+$ & $\mathbf{0 , 3 8}$ & 0,28 & $\underline{0,09}$ & 0,20 & 0,22 & 0,29 \\
\hline 8 & male & $U-$ & $\mathbf{0 , 4 1}$ & 0,05 & 0,02 & $\underline{0,01}$ & 0,09 & 0,27 \\
\hline 9 & $(3,1)$ & $U^{o}$ & $\underline{0,21}$ & 0,67 & $\mathbf{0 , 8 8}$ & 0,79 & 0,68 & 0,44 \\
\hline 10 & all & $U+$ & 0,32 & 0,32 & 0,23 & $\underline{0,25}$ & 0,23 & $\mathbf{0 , 3 3}$ \\
\hline 11 & male & $U-$ & 0,46 & 0,06 & $\underline{0,04}$ & 0,05 & 0,16 & 0,25 \\
\hline 12 & $(*, 1)$ & $U^{o}$ & $\underline{0,22}$ & 0,62 & 0,73 & 0,69 & 0,61 & 0,42 \\
\hline 13 & young & $U+$ & 0,44 & 0,44 & 0,37 & 0,40 & $\underline{0,36}$ & 0,42 \\
\hline 14 & female & $U-$ & 0,49 & 0,07 & 0,09 & $\underline{0,05}$ & 0,19 & 0,16 \\
\hline 15 & $(1,2)$ & $U^{o}$ & $\underline{0,07}$ & 0,49 & 0,53 & 0,56 & 0,45 & 0,42 \\
\hline 16 & senior & $U+$ & 0,38 & 0,39 & $\underline{0,17}$ & 0,30 & 0,38 & 0,44 \\
\hline 17 & female & $U-$ & 0,51 & 0,07 & $\underline{0,03}$ & 0,11 & 0,18 & 0,24 \\
\hline 18 & $(2,2)$ & $U^{o}$ & $\underline{0,11}$ & 0,54 & 0,81 & 0,59 & 0,44 & 0,32 \\
\hline 19 & old & $U+$ & 0,43 & 0,18 & $\underline{0,10}$ & 0,16 & 0,25 & 0,37 \\
\hline 20 & female & $U-$ & 0,41 & 0,02 & $\underline{0,01}$ & 0,02 & 0,12 & 0,29 \\
\hline 21 & $(3,2)$ & $U^{o}$ & $\underline{0,16}$ & 0,80 & 0,89 & 0,82 & 0,63 & 0,34 \\
\hline 22 & all & $U+$ & 0,41 & 0,34 & $\underline{0,21}$ & 0,28 & 0,33 & 0,41 \\
\hline 23 & female & $U_{-}$ & 0,47 & 0,05 & $\underline{0,04}$ & 0,06 & 0,16 & 0,23 \\
\hline 24 & $(*, 2)$ & $U^{o}$ & $\underline{0,11}$ & 0,61 & 0,75 & 0,65 & 0,51 & 0,36 \\
\hline 25 & all & $U+$ & $\mathbf{0 , 3 9}$ & 0,36 & 0,39 & 0,33 & $\underline{0,28}$ & 0,39 \\
\hline 26 & young & $U-$ & 0,48 & 0,08 & $\underline{0,07}$ & $\underline{0,07}$ & 0,21 & 0,18 \\
\hline 27 & $(1, *)$ & $U^{o}$ & $\underline{0,13}$ & 0,56 & 0,54 & 0,60 & 0,51 & 0,43 \\
\hline 28 & all & $U+$ & 0,32 & 0,39 & $\underline{0,19}$ & 0,30 & 0,32 & 0,39 \\
\hline 29 & senior & $U_{-}$ & $\mathbf{0 , 5 0}$ & 0,05 & $\underline{0,03}$ & 0,08 & 0,16 & 0,25 \\
\hline 30 & $(2, *)$ & $U^{o}$ & $\underline{0,18}$ & 0,55 & 0,78 & 0,62 & 0,51 & 0,35 \\
\hline 31 & all & $U+$ & $\mathbf{0 , 4 0}$ & 0,23 & $\underline{0,10}$ & 0,18 & 0,24 & 0,33 \\
\hline 32 & old & $U-$ & 0,41 & 0,03 & $\underline{0,02}$ & $\underline{0,02}$ & 0,11 & 0,28 \\
\hline 33 & $\left(3,{ }^{*}\right)$ & $U^{o}$ & $\underline{0,19}$ & 0,74 & 0,89 & 0,80 & 0,66 & 0,39 \\
\hline 34 & & $U+$ & $\mathbf{0 , 3 7}$ & 0,33 & $\underline{0,22}$ & 0,27 & 0,28 & $\mathbf{0 , 3 7}$ \\
\hline 35 & all & $U$ & 0,47 & 0,06 & $\underline{0,04}$ & 0,06 & 0,16 & 0,24 \\
\hline 36 & $(*, *)$ & $U^{o}$ & $\underline{0,17}$ & 0,61 & 0,74 & 0,67 & 0,56 & 0,39 \\
\hline
\end{tabular}

TABLE II. CAPACITY OF DETERMINATIONS "GROUP $\rightarrow$ ASSESSMENT"

\begin{tabular}{|c|c|c|c|c|c|c|c|c|}
\hline & \multirow{2}{*}{$\begin{array}{l}\text { Ca- } \\
\text { pa- } \\
\text { sity }\end{array}$} & & \multicolumn{6}{|c|}{ Survey questions } \\
\hline & & & 1 & 2 & 3 & 4 & 5 & 6 \\
\hline № & & & 1 & 2 & 3 & 4 & 5 & 6 \\
\hline 1 & \multirow{11}{*}{$V+$} & young male & 0,13 & 0,12 & 0,27 & 0,14 & $\underline{0,10}$ & 0,14 \\
\hline 2 & & senior male & $\underline{0,13}$ & 0,22 & 0,18 & 0,21 & 0,18 & 0,17 \\
\hline 3 & & old male & 0,15 & 0,13 & $\underline{0,06}$ & 0,11 & 0,12 & 0,12 \\
\hline 4 & & young female & 0,18 & 0,20 & 0,26 & 0,22 & 0,19 & $\underline{0,17}$ \\
\hline 5 & & senior female & 0,21 & 0,23 & $\underline{0,15}$ & 0,22 & 0,27 & 0,24 \\
\hline 6 & & old female & 0,19 & 0,09 & $\underline{0,07}$ & 0,10 & 0,14 & 0,16 \\
\hline 7 & & all male & 0,42 & 0,47 & $\mathbf{0 , 5 2}$ & 0,46 & $\underline{0,39}$ & 0,43 \\
\hline 8 & & all female & 0,58 & 0,53 & 0,48 & 0,54 & 0,61 & 0,57 \\
\hline 9 & & all young & 0,32 & 0,32 & $\mathbf{0 , 5 3}$ & 0,36 & $\underline{0,29}$ & 0,31 \\
\hline 10 & & all senior & 0,34 & 0,46 & $\underline{0,33}$ & 0,43 & 0,44 & 0,41 \\
\hline 11 & & all old & 0,34 & 0,22 & $\underline{0,14}$ & 0,21 & 0,26 & 0,28 \\
\hline 12 & \multirow{11}{*}{$V-$} & young male & 0,15 & 0,25 & 0,18 & 0,24 & 0,21 & $\underline{0,12}$ \\
\hline 13 & & senior male & 0,20 & $\underline{0,13}$ & 0,18 & 0,18 & 0,18 & 0,21 \\
\hline 14 & & old male & 0,13 & 0,13 & 0,09 & $\underline{0,03}$ & 0,09 & 0,17 \\
\hline 15 & & young female & 0,16 & 0,19 & 0,36 & 0,12 & 0,18 & $\underline{0,10}$ \\
\hline 16 & & senior female & 0,22 & 0,25 & $\underline{0,14}$ & $\mathbf{0 , 3 6}$ & 0,22 & 0,20 \\
\hline 17 & & old female & 0,14 & 0,06 & $\underline{0,05}$ & 0,06 & 0,12 & 0,20 \\
\hline 18 & & all male & 0,48 & $\mathbf{0 , 5 0}$ & $\underline{0,45}$ & $\underline{0,45}$ & 0,48 & $\mathbf{0 , 5 0}$ \\
\hline 19 & & all female & 0,52 & $\underline{0,50}$ & 0,55 & 0,55 & 0,52 & $\underline{0,50}$ \\
\hline 20 & & all young & 0,31 & 0,44 & 0,55 & 0,36 & 0,39 & $\underline{0,23}$ \\
\hline 21 & & all senior & 0,42 & 0,38 & $\underline{0,32}$ & 0,55 & 0,40 & 0,41 \\
\hline 22 & & all old & 0,28 & 0,19 & 0,14 & $\underline{0,09}$ & 0,21 & 0,36 \\
\hline 23 & \multirow{11}{*}{$V^{0}$} & young male & $\mathbf{0 , 1 7}$ & 0,15 & $\underline{0,11}$ & 0,14 & 0,15 & 0,16 \\
\hline 24 & & senior male & 0,29 & $\underline{0,18}$ & 0,19 & $\underline{0,18}$ & 0,20 & 0,19 \\
\hline 25 & & old male & 0,19 & 0,16 & 0,18 & 0,18 & 0,18 & $\underline{0,17}$ \\
\hline 26 & & young female & $\underline{0,06}$ & 0,12 & 0,11 & 0,13 & 0,12 & 0,16 \\
\hline 27 & & senior female & $\underline{0,13}$ & 0,18 & 0,22 & 0,18 & 0,16 & 0,16 \\
\hline 28 & & old female & 0,16 & 0,21 & 0,20 & 0,20 & 0,19 & $\underline{0,15}$ \\
\hline 29 & & all male & 0,65 & 0,49 & $\underline{0,48}$ & 0,50 & 0,53 & 0,53 \\
\hline 30 & & all female & $\underline{0,35}$ & 0,51 & $\mathbf{0 , 5 2}$ & 0,50 & 0,47 & 0,47 \\
\hline 31 & & all young & 0,23 & 0,27 & $\underline{0,22}$ & 0,27 & 0,27 & 0,33 \\
\hline 32 & & all senior & 0,41 & 0,35 & 0,41 & 0,36 & 0,36 & 0,36 \\
\hline 33 & & all old & 0,35 & 0,38 & $\mathbf{0 , 3 8}$ & 0,38 & 0,37 & 0,32 \\
\hline
\end{tabular}

TABLE III. SIGNIFICANCE COEFFICIENTS

\begin{tabular}{|c|c|c|c|c|c|c|}
\hline \multirow{2}{*}{$\begin{array}{c}\text { Survey } \\
\text { question }\end{array}$} & $\begin{array}{c}\text { Young } \\
\text { men }\end{array}$ & $\begin{array}{c}\text { Senior } \\
\text { men }\end{array}$ & $\begin{array}{c}\text { Old } \\
\text { men }\end{array}$ & $\begin{array}{c}\text { Young } \\
\text { women }\end{array}$ & $\begin{array}{c}\text { Senior } \\
\text { women }\end{array}$ & $\begin{array}{c}\text { Old } \\
\text { women }\end{array}$ \\
\hline 1 & 1 & 2 & 3 & 1 & 2 & 3 \\
\hline 2 & 3 & 2 & 1 & 3 & 2 & 1 \\
\hline 3 & 3 & 2 & 1 & 3 & 2 & 1 \\
\hline 4 & 2 & 2 & 1 & 2 & 2 & 1 \\
\hline 5 & 3 & 2 & 1 & 3 & 2 & 1 \\
\hline 6 & 2 & 3 & 1 & 2 & 3 & 1 \\
\hline
\end{tabular}


TABLE IV. INTENSITY OF DETERMINATIONS "GROUP $\rightarrow$ ASSESSMENT" CALCULATED WITH SIGNIFICANCE COEFFICIENTS

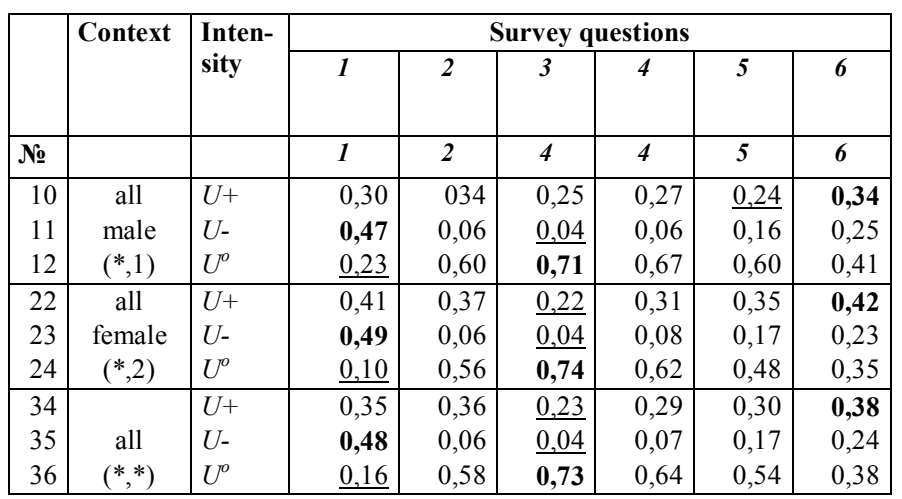

TABLE V. CAPACITY OF DETERMINATIONS "GROUP $\rightarrow$ ASSESSMENT" CALCULATED WITH SIGNIFICANCE COEFFICIENTS.

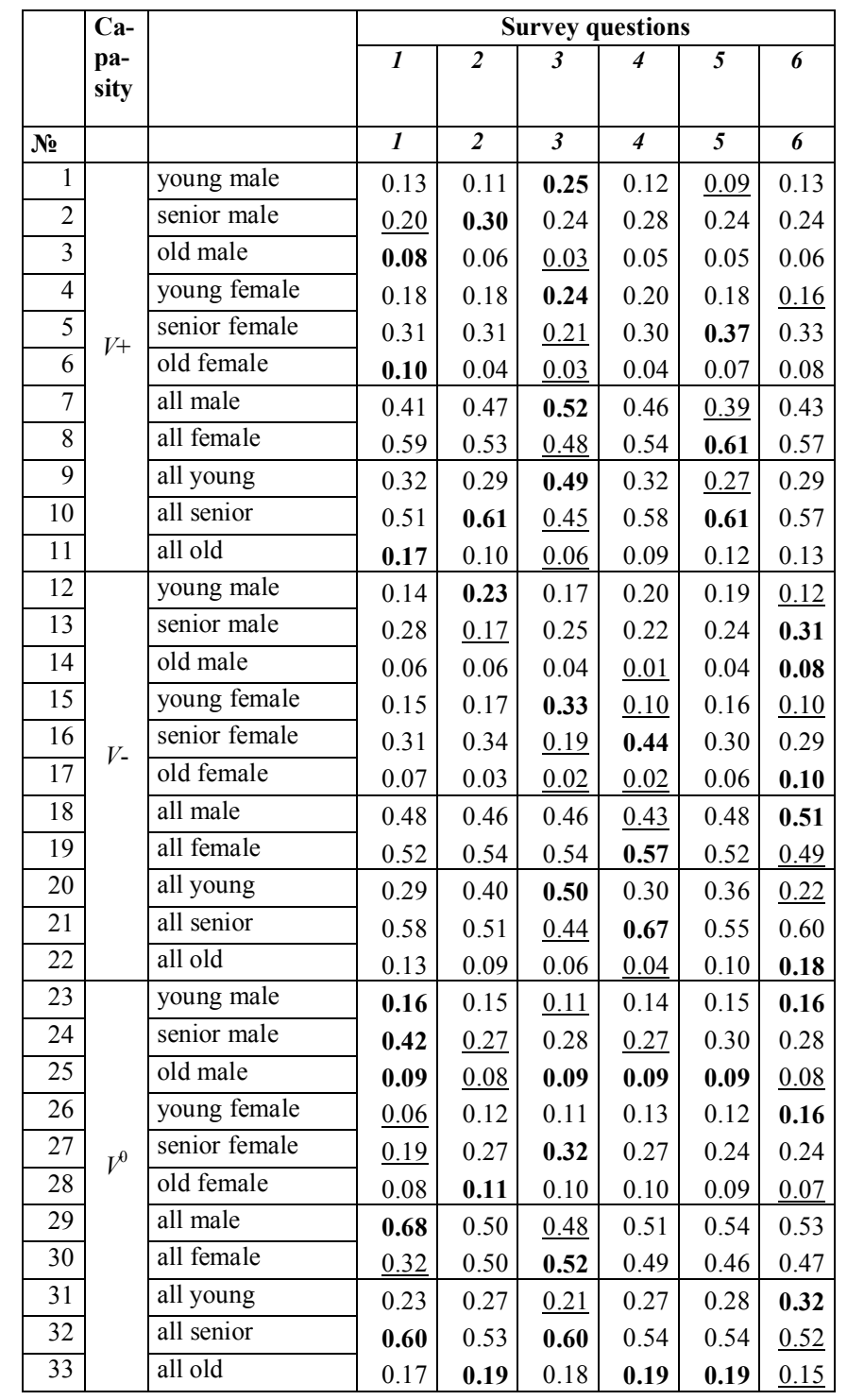

Comparison of the capacities in tables 2 and 5 shows that the values in lines $1,4,7,8$ (positive attitude), 12, 15, 19, 20 (negative attitude), 23, 26, 31, 29, 30 (neutral attitude) are the same or almost the same. In the table 5, in contrast with table 2, positive attitude $V^{+}$demonstrates an increased value of capacity at rows $2,5,10$, increased value of capacity of the negative attitude of $V$ at lines 13,16,17, 21, and increase in the capacity of the neutral attitude $V^{0}-$ lines $24,27,32$. The decrease in the capacity of the positive attitude can be noticed in the values at rows $3,6,9,11$, the decrease in the capacity of the negative attitude can be found in lines 14, 18, 22, and the decrease in the capacity of the neutral attitude at lines 25,28 , 33.

The results of calculating the intensity and capacity of the studied determination, taking into account the importance of the respondents' opinion, showed an increase in the positive attitude, a decrease in the evaluation of the negative attitude and a remarkable decrease in the assessment of the indifferent attitude of the population to the problems of the district in comparison to the case of the equal importance of the respondents' opinions.

\section{CONCLUSION}

Usage of the significance of the respondents' opinions in DAW is not just the next level of structuring with DA (introduction of additional classification properties), it allows us to fill the assessments with objective content that more accurately and subtly reflects the reality.

The same role is played by both the most important characteristics of determinations - intensity and capacity. The appearance in the determinacy analysis of a new "figure" - an assessment of the significance of the respondent's opinion changes the interpretation of these characteristics.

\section{REFERENCES}

[1] M. Hoxley, "Purchasing UK public sector property and construction professional services: competition v quality", European Journal of Purchasing \& Supply Management. vol. 7, 2001, pp.133-139.

[2] K. Deininger and P. Mpuga, "Does Greater Accountability Improve the Quality of Public Service Delivery? Evidence from Uganda", World Development, vol. 33 (1), 2005, pp. 171-191.

[3] B. Cuadrado-Ballesteros, García-Sánchez Isabel-María, and PradoLorenzo José-Manuel, "Effect of modes of public services delivery on the efficiency of local governments: A two-stage approach", Utilities Policy, vol. 26, 2013, pp. 23-35.

[4] F. Djellal, F. Gallouj, and I. Miles, "Two decades of research on innovation in services: Which place for public services?," Structural Changes and Economic Dynamics, vol. 27, 2013, pp. 98-117.

[5] V.L. Purcărea, I.R. Gheorghea, and C.M. Petrescu, "The Assessment of Perceived Service Quality of Public Health Care Services in Romania Using the SERVQUAL Scale". Procedia Economics and Finance, vol. 6, 2013, pp. 573-585.

[6] H. Umegaki, M. Yanagawa, Z. Nonogaki, H. Nakashima, M. Kuzuya, and H. Endo, "Burden reduction of caregivers for users of care services provided by the public long-term care insurance system in Japan". Archives of Gerontology and Geriatrics, vol. 58, 2014, pp. 130-133.

[7] S.E. Martynova and O.G. Maslennikova, "The "service" model of the competences of the municipal employee as a basis of vocational training: Russian experience". Procedia - Social and Behavioral Sciences, vol. 174, 2014, pp. 2716-2720.

[8] Y.G. Dmitriev, S.E. Martynova, and Y.K. Ustinov, "On the validity of quantitative assessment of socium satisfaction with the quality of public services: the case of municipalities of Russia." Proceedings of the 3rd International conference on development of sociology and demography in Eurasia (Vienna, April 20, 2015). "East West" Association for 
Advanced Studies and Higher Education GmbH, 2015, pp. 19-26. (in Russian).

[9] Svetlana E. Martynova, Yuri Glebovich Dmitriev, Marina M. Gajfullina, and Yulia A. Totskaya. " "Service" Municipal Administration as Part of the Development of Youth Entrepreneurship in Russia." Social Indicators Research, Vol. 133, Issue 3, September 2017, pp.1151-1164/

[10] S. V. Chesnokov, "Determinacy analysis of social-economic data". Moscow: Nauka (in Russian), 1982.

[11] S. V. Chesnokov and P. A. Luelsdorff, "Determinacy analysis and theoretical orthography." Theoretical Linguistics, vol. 17, 1991, pp. 1-3.

[12] P.A. Luelsdorff and S.V. Chesnokov, "Determinacy form as the essence of language.Prague Linguistic Circle Papers," 2, 1996, pp. 205-234.

[13] G. Lind and R. Kuusik, "New developments for determinacy analysis: diclique-based approach". WSEAS Transactions on Information Science and Applications. 5 (10), 2008, pp. 1448-1459.

[14] A. N. Kolmogorov, "Foundations of the Theory of Probability". (2nd ed.). New York:Chelsea Pub. Co. 1956.

[15] Yuri G. Dmitriev, Svetlana E. Martynova, Peter F. Tarassenko and Yuri K. Ustinov, "Application of Determinacy Analysis to the Study of Citizen Satisfaction with the Service-Based Public Management". Mediterranean Journal of Social Sciences, vol. 6, No 6, S2. November, 2015, pp. 444-452. 